\title{
Effect of Aqueous Extract of Liquorice (G. Glabra L) in Treatment of Stress Induced Gastric Ulcer in Wistar Rats
}

\author{
Saksham Mathur', Cheryl Sarah Philipose'2, Ganaraja B,*
}

\section{Saksham Mathur', Cheryl Sarah Philipose $^{2}$, Ganaraja B,**}

'Kasturba Medical College, Mangalore (A constituent of Manipal Academy of Higher Education) INDIA.

${ }^{2}$ Department of Pathology, Kasturba Medical College, Mangalore (A constituent of Manipa Academy of Higher Education) INDIA.

${ }^{3}$ Additional Professor, Physiology, Kasturba Medical College, Centre for Basic Sciences, Bejai post, Mangalore - 575004. (A constituent of Manipal Academy of Higher Education, Manipal) INDIA.

\section{Correspondence}

\section{Ganaraja B}

Additional Professor, Physiology, Kasturba Medical College, Centre for Basic

Sciences, Bejai post, Mangalore - 575004

(A constituent of Manipal Academy of

Higher Education, Manipal) INDIA.

Phone no: 00919449642150

E-mail: ganaraj.b@gmail.com

History

- Submission Date: 04-10-2019;

- Review completed: 14-10-2019;

- Accepted Date: 18-10-2019.

\section{DOI : 10.5530/pj.2019.11.233}

Article Available online http://www.phcogj.com/v11/i6s

\section{Copyright}

(C) 2019 Phcogj.Com. This is an openaccess article distributed under the term of the Creative Commons Attribution 4.0 International license.

\section{ABSTRACT agent to prevent the peptic ulcer in vulnerable subjects. \\ INTRODUCTION AND REVIEW OF LITERATURE}

Background: Peptic ulcer is a disease affecting a large number of people, caused due to various reasons including infection with $\mathrm{H}$ pylori, consumption of alcohol, NSAIDs and stress. Although not a life-threatening disease, it causes undue distress and discomfort and accounts for increased time off from work thereby leading to manpower and economic losses. In this condition, histamine receptor blockers provide relief. Objectives: Natural remedies for peptic ulcer have not been effectively utilized in clinical set up. In the present study, we evaluated the effect of water extract of Glycyrrhiza Glabra L, commonly known as Liquorice on stressinduced gastric inflammation. Materials \& Methods: Liquorice extract was prepared. Male Wistar rats ( $n=5$ in each group) were procured from the central animal house and divided into four groups namely Group 1(control); Group 2 (low dose treatment); Group 3 (high dose treatment) and group 4 (prophylactic). They were housed individually and subjected to restraint stress in PVC pipes for 2 hours daily and their stomach was examined for ulcer in Licorice (oral) fed groups and control. Results: Control group showed the inflammatory changes, ulcer index showed a significant lesion, whereas the animals treated with low dose and high dose showed proportionate decrease in the severity of inflammation as evidenced by the histological features. Fourth group of rats which was treated prophylactically before they were subjected to stress, showed no sign of stress-induced inflammatory changes in the gastric mucosa. Conclusion: The results of this study strongly suggested that the G Glabra extract reduces the inflammation and relieves the ulcers and also it can be used as a prophylactic

Key words: Glycyrrhiza glabra, Immobilization stress, Peptic ulcer, Prophylactic use.

Peptic ulcer is a common ailment which has a prevalence rate of about $0.2 \%$ in the population worldwide. The symptoms include dysphagia, recurrent vomiting, weight loss, or blood in stools. Gastric mucosal damage leading to ulceration occurs due to stress, ${ }^{1}$ use of acetylsalicylic acid (ASA), NSAIDs. ${ }^{2}$ It has also been known to occur following bacterial infection, particularly by Helicobacter pylori. ${ }^{3,4}$ Hypersecretion of gastrin from gastrin secreting tumors have also been implicated in development of gastric ulcers. ${ }^{5}$ Alcohol, histamine and capsaicin also cause disruption of gastric mucosa leading to ulcers.

Currently peptic ulcers are treated using multiple interventions depending upon the etiology. It includes treating $H$ pylori infection, by antibiotics; Antihistamines like Ranitidine, and proton pump inhibitors. Antacids are used in milder cases. Avoidance of oral intake of NSAIDs and Aspirin, and other gastric irritants also are useful. However, some traditional treatments were also employed which are less effective.

In a recent study, ${ }^{6}$ the effect of Liquorice and a combination of other herbs namely, Pulasari (Alyxia reinwardtii), and Sembung (Blumea balsamifera) including a mixture of all these were tested in Gastric ulcer induced with Aspirin in rats. The researchers noted the gastric protective effects of these substances. Further, others ${ }^{7}$ have demonstrated that Liquorice extract is effective in prevention of adhesion of H.pylori in the gastric mucosa and thus prevent the infection and hence prevent gastric ulcer. Momeni et al. ${ }^{8}$ suggested that the G Glabra extracts are as effective in prevention of H. Pylori as bismuth, recommending that the patients who are unable to take bismuth may be effectively treated with Liquorice extract.

Meta-analysis of research data on the studies involving treatment with $G$ Glabra extract revealed that it caused an increased diastolic blood pressure in some trials. ${ }^{9}$ The glycyrrhetinic acid present in the plant is believed to be responsible for this action. Foster $\mathrm{S}$ et al. ${ }^{10}$ reported a case of a patient with persistent hypertension with no apparent cause, which was later attributed to consumption of Liquorice tea, which coincided with each episode of symptoms of hypertension. On stopping intake of Liquorice tea, the patient turned normal. Similar incidences were also reported in subsequent case reports from India. ${ }^{11}$

Experimental gastric ulcer can be induced in many ways in animals. Some tested methods include injection of acetic acid. ${ }^{12}$ Others, researchers have used water immersion restrain stress. ${ }^{13}$ Many other methods of inducing ulcers include aspirin use, 
alcohol consumption etc. In the present study, we preferred the restraint stress in rats, which also resulted in inflammatory changes in the gastric mucosa.

In the present study we evaluated the use of the herbal extract of G. Glabra (commonly known as Liquorice) to treat the induced gastric ulcers in the rat. We fed the animals which were exposed to immobilization stress, with low dose and high dose of Liquorice extract. The treatment groups were tested for the ulcers in the mucosa of stomach and compared with the control untreated - stressed animals. In another group, we fed the animal with Liquorice extract in the days the stress was induced, to evaluate if the Liquorice is already there in the stomach, then ulceration will appear or not. This gave us the information regarding the 'prophylactic use' of Liquorice decoction in the prevention of the damage to the gastric mucosa. This will help in developing an effective herbal remedy for the disease, which is accessible and inexpensive and with least side effects.

\section{MATERIALS AND METHODS}

Male Wistar albino rats ( $\mathrm{n}=5$ each) weighing 150-200 g were procured from the central animal house of our institution. They were housed in standard laboratory conditions in plastic cages with paddy husk bed and water and food pellets were made available $a d$ lib. They were divided into following groups, viz. Control group 1; Treatment Group 2: 5 days post stress induction - low dose; Group 3 - treatment - 5 days post stress induction - high dose (Total $20+4$ rats). Group 4: Prophylactic treatment -5 days Stress + Liquorice.

Clearance for the study from the Institutional Ethical committee for the experiments using animal, was obtained prior to commencement of the study. The animals were housed in individual cages and subjected to fasting for 24-36 hours prior to stress. Ulcers was experimentally induced by method immobilization stress. ${ }^{1,14,15}$ Following treatment and observations, the stomach was dissected out for observation and measurement of ulcers.

\section{Preparation of the water extract of Liquorice}

Liquorice powder was obtained from the market (Brand: Zandu Pharma, manufactured by Emami Limited. India). $10 \mathrm{~g}$ of this powder was mixed with $250 \mathrm{ml}$ of water and the extract was prepared using Soxhlet's apparatus. ${ }^{16}$ This extract was stored in the refrigerator and diluted to required dosage just before feeding the animals.

\section{Procedure for inducing stress}

Rats were subjected to stress by immobilization. They were kept in a PVC pipe of about 7 inches long and having a diameter of 1.5 inches. The ends were covered by "end caps". Rats were kept in this position for 2 hours at a stretch every day for five consecutive days. At the end of this stress induction, the control rats were dissected and the stomach was removed, opened through the greater curvature and washed with normal saline, to observe the occurrence of ulcers. The inflamed mucosa was the confirmatory test of the Ulcers. The ulcer index was calculated using the formula given below. ${ }^{15}$

\section{Procedure of feeding}

The rats were orally fed with the calculated dose of the stored water extract using an oral gavage, every morning at 10.00 AM. The group receiving prophylactic dosage was fed with the extract before the restraining.

\section{Experimental procedure}

The control rats were sacrificed by inducing deep ether anesthesia and opening the heart to bleed. Their stomach was dissected out, cut open along the greater curvature and studied for anatomical and pathological changes. Ulceration in the stomach following exposure to the immobilization stress was confirmed. The Stomach of the stress exposed rats were examined for inflammation and ulcers.

The Low dose treatment group received $100 \mathrm{mg} / \mathrm{kg}$ body equivalent of the Liquorice water extract every day at 12.00 noon for 7 days, following which they were sacrificed and their stomach was dissected and observed for ulcers.

The high dose group received $200 \mathrm{mg} / \mathrm{kg}$ body weight equivalent of the Liquorice following the stress exposure, following the same time schedule as above.

The next group received the Liquorice treatment along with the exposure to stress, following the treatment period their stomach was dissected out and tested for Ulcer.

Ulcer index was calculated following the method described previously. The number and severity of lesions were evaluated. The following scores were used: light (I), presence of edema, hyperemia and single petechiae; moderate (II), presence of submucosal hemorrhagic lesions with small erosions; severe (III), presence of hemorrhagic lesions with severe erosions.

Ulcer Index $(\mathrm{UI})=(\mathrm{nI})+(\mathrm{nII}) 2+(\mathrm{nIII}) 3 \backslash$ Number of animals Where: $\mathrm{n}$ is the number of lesions.

The preventive effect was calculated by the method of Basile et al. ${ }^{17}$ as follows: Prevention index (\%) = UI Control - UI Treated IUI Control $\times$ 100 UI Control $=$ ulcer index in the negative control group UI Treated $=$ ulcer index in the group receiving HEGG. ${ }^{18}$

The rats were subjected to treatment with Liquorice water decoction by using Soxhelt's apparatus, known weight of the dry powder procured from local market. They were tested for a period of five days following inducing ulcers by restrain stress. The ulcers were evaluated by dissection of stomach and measuring them after five days, and the ulcer index was calculated. Comparison was done between the data from normal control $\&$ stress induced treated and stress induced untreated rats. In the other group, untreated and treated animals were evaluated for presence or absence of ulcers on 6th day. Following the completion of experimental procedure, the stomach tissue is processed for histological examination by sectioning the wax blocks and observing the $\mathrm{H} \& \mathrm{E}$ stained slices under microscope for the signs of ulceration and inflammatory changes by following standard histopathology procedures.

\section{RESULTS}

Results were analyzed using appropriate statistical methods. We found severe inflammatory changes in the mucosa of stomach among the rats exposed to immobilization stress. The mucosa was reddish, but the ulceration was found only in patches (Figures 1 and 2).

In the treated group, the mucosa was pale pink with milder degree of inflammation (Figure 2).

Effect of Liquorice Treatment was dose dependent, and the low dose group showed mild inflammation, while high dose of Liquorice treatment showed near normal mucosa.

In the next group, we fed the animals with Liquorice extract daily before exposing the rats to immobilization stress. We found that there was neither ulceration nor inflammation in such animals.

Outcome of the result: Ulcer index was lower after the treatment with Liquorice extract, in the untreated control it was high.

\section{GROSS FEATURES}

1. Control group: Severe inflammatory changes in the mucosa of stomach was found among the rats exposed to immobilization stress. 


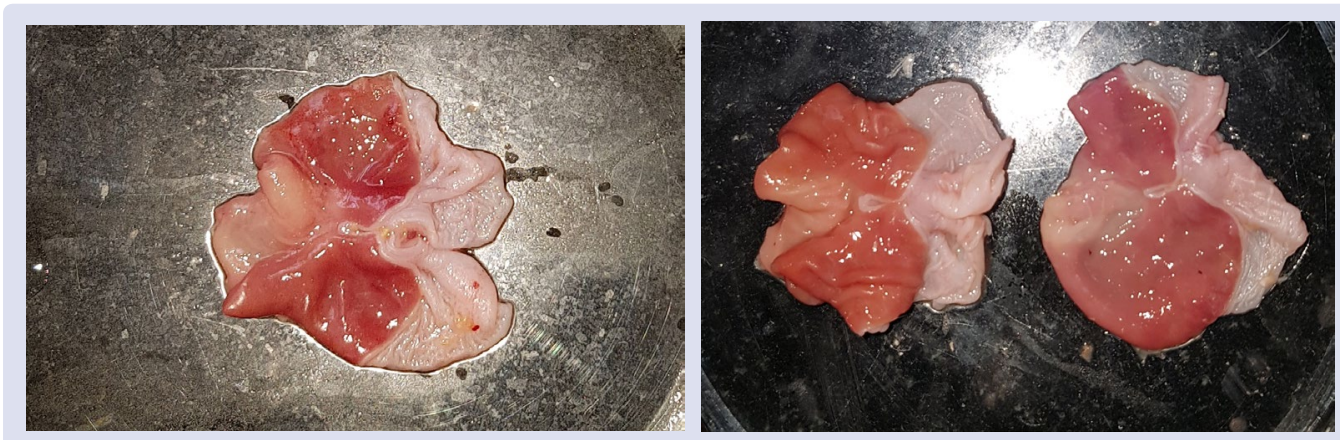

Figure 1: Control Group: Severe inflammatory changes in the mucosa of stomach was found among the rats exposed to immobilization stress. The mucosa was reddish, but the Ulceration was found only in patches.

Section of stomach showing inflamed mucosa in control group Ulcer Index (UI) Control $=(5 \times 1)+(4 \times 2)+(0 \times 3) / 5 \mathrm{UI}=$ 2.6

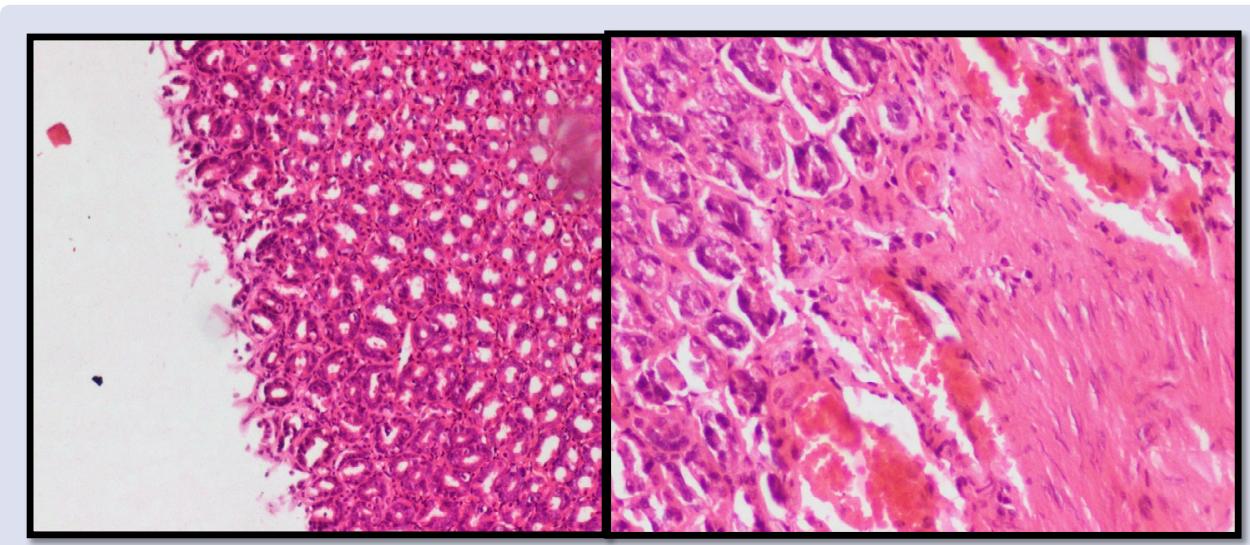

Figure 2: Comparison of stomachs of untreated rats (left) and rats which received prophylactic treatment Control group: H\&E stained histological features of the stress induced Ulcer in rat stomach.

The mucosa was reddish, but the Ulceration was found only in patches (Figure 1).

2. Treatment group: In the treated group, the mucosa was pale pink and less signs of inflammation was seen.

Effect of Liquorice Treatment was dose dependent, and the low dose group (Figure 2) showed mild inflammation, while high dose of Liquorice treatment showed almost normal mucosa.

(a) Ulcer Index (UI) Treatment $($ Low dose $)=(5 \times 1)+(0 \times 2)+(0 \times 3) / 5$

$\mathrm{UI}=1$

Preventive Index (low dose treatment $)=2.6-1 / 2.6 \times 100$

PI (low dose $)=61.5 \%$

(b) Ulcer Index (UI) Treatment (High dose) $=0 / 5=0$

Preventive Index $($ High dose treatment $)=2.6-0 / 2.6{ }^{\star} 100$

PI $($ high dose $)=100 \%$

3. Prophylaxis group: In the next group, the animals were fed with Liquorice extract daily before exposing the rats to immobilization stress. We found that there was no ulceration/inflammation in such animals.

Ulcer Index (UI) Prophylaxis $=0 / 5=0$

Preventive Index $($ Prophylaxis $)=2.6-0 / 2.6 * 100$

PI (prophylaxis) $=100 \%$
Outcome of the result: Ulcer index was lowered after the treatment with Liquorice extract, in the untreated control it was high.

Microscopic Features (Table 1): Occurrence of Ulcers (+) and inflammatory features in groups of control, low \& high dose and prophylactic treatment in animals. Mucosa erosion was observed following exposure to stress. Edema was not found. Hyperemic changes were observed in controls and in high dose treated group it was not observed. Neutrophil was seen in controls and low dose treated group, while it was not observed in high dose group.

Histopathology (Figures 3-5): Histopathological examination of the stomach sections revealed the inflammatory changes in the stress induced ulcer controls. The symptoms were alleviated in the treated group and it appeared to be dose dependent, viz. in high dose of licorice extract, the stomach showed little inflammation. The same observation

Table 1: Microscopic features: Occurrence of ulcers ( + ) and inflammatory features in groups of control, low \& high dose and prophylactic treatment in animals.

\begin{tabular}{ccccc}
$\begin{array}{c}\text { Microscopic } \\
\text { Features }\end{array}$ & Control & Low dose & High dose & Prophylaxis \\
\hline Erosion & + & + & + & - \\
Edema & - & - & - & - \\
Hyperemia/ & & & & + \\
Congestion & + & + & - & \\
/Hemorrhage & & & & \\
Neutrophils & + & + & Occasional & Occasional \\
Lymphocytes & + & + & Occasional & Occasional \\
\hline
\end{tabular}




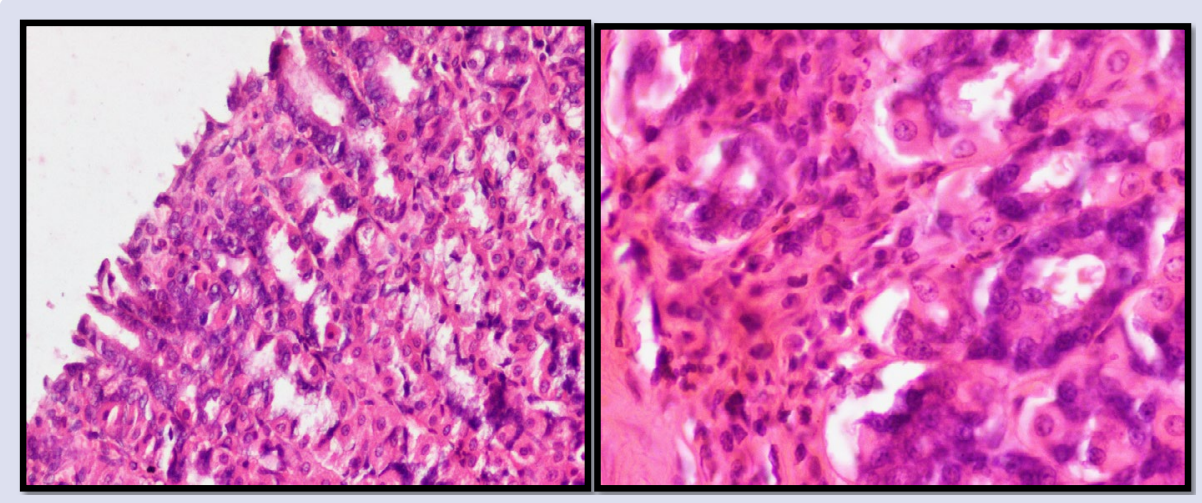

Figure 3a\&3b: a. Mucosa of the stomach showing extensive mucosal erosions (H\&E,100x), b. Lamina propria shows many congested vessels and hemorrhage (H\&E,200x).

Low dose treatment group

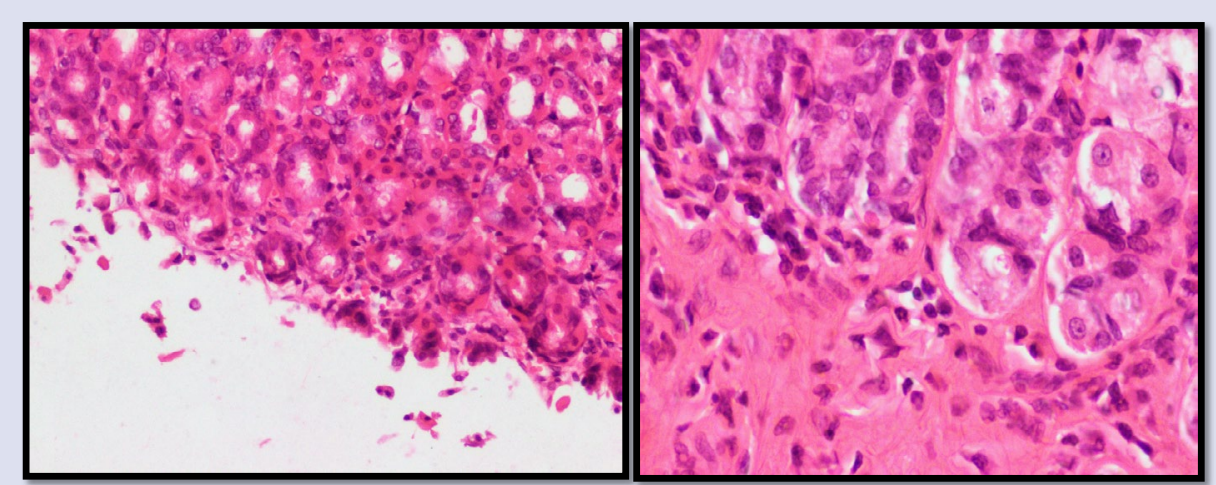

Figure 4a\&4b: a. Mucosa of the stomach showing extensive erosions (H\&E,200x), b. Lamina propria shows dense inflammatory infiltrate composed predominantly of neutrophils admixed with few lymphocytes (H\&E,400x)

High dose treatment group

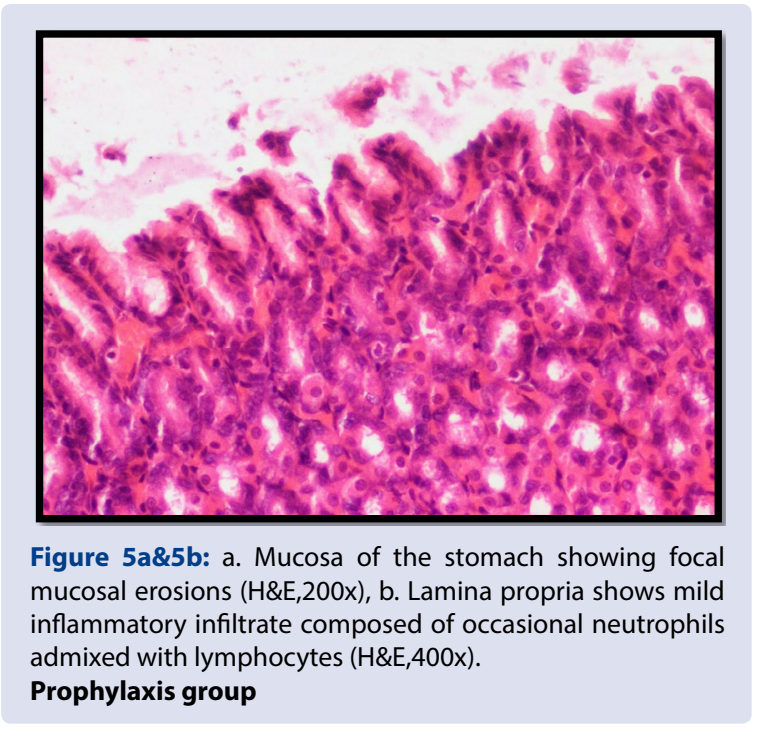

was observed in the group given Licorice extract prophylactically during exposure to stress. Such animals did not show any lesions in the mucosa.

\section{DISCUSSION}

Peptic ulcer commonly affects a number of people worldwide. The problem of acidity is all pervasive. While $H$. pylori has been implicated in the causation, it has been known to occur even in the absence of this bacteria. With changing lifestyle and food habits, the incidence of this condition is increasing. Consumption of alcohol and vinegar along with spicy food also contributes to the occurrence of ulcers. Smoking tobacco and excessive coffee intake can also cause ulceration. Tumors secreting gastrin is yet another cause. However, most important factor leading to gastric ulceration remains stress. ${ }^{19}$ Stress causes ulcers by 
increasing the vagal stimulation, releasing acetyl choline increasing acid secretion in stomach. ${ }^{20}$

Traditionally, several lines of treatments have been followed to relieve the discomfort and treat the peptic ulcers. The following medications are used in the management of stress; Sucralfate: Primary agent for prophylaxis; Histamine 2 (H2) receptor blockers (e.g., ranitidine, famotidine, cimetidine, nizatidine); Proton pump inhibitors (e.g., esomeprazole, pantoprazole). Traditionally many different treatments were suggested for alleviation of gastric ulcer in the alternative medicine, but many of them had limited use. One of the most potent candidate herb in the treatment of ulcers was Liquorice. ${ }^{21}$ Many authors suggested Liquorice had a role in wound healing. ${ }^{22}$ They applied Liquorice extract on the wound found encouraging results.

Many authors suggested a role for the Liquorice extract in healing gastric ulcer. However, there is no consensus in the methodology of using it.

In the present study, we found inflammation of the gastric mucosa and ulceration in the stomach in the immobilization stress exposed animals. One week stress exposure for 2 hours daily was adequate to produce inflammatory changes in the mucosa.

We chose to study the effect of Liquorice extract in rats exposed to immobilization stress. This model mimicked the natural process of ulceration rather than acid induced or drug induced gastric ulcers. In the immobilization stress, the natural over stimulation of mucosa takes place by excess secretion of Gastrin hormone and vagal stimulation, causing over secretion of $\mathrm{HCl}$. Therefore, we found more of erythema and generalized inflammation of mucosa, with interspersed patches of ulcers. In other models, the ulcer patches are produced on sites of contact of acid; On the other hand, methods such as pyloric ligation was much more traumatic.

We found that the water extract of Liquorice given using oral gavage was effective in reducing the inflammatory changes and ulceration in immobilization stress exposed animals. We also found that those animals treated with higher dose has lesser redness in the mucosa, which suggested that the dose dependent benefit of Liquorice extract.

Further we investigated the possibility of usage of Liquorice extract as a protective agent against the inflammatory changes, if pretreated, before the exposure to the stress. In this group we found that the inflammatory changes were minimal and no significant erythema was seen in the mucosa. Thus we postulate that Liquorice could be a prophylactic agent which can prevent the gastric ulcer, if given before the ulcer producing agents. It will be useful if Liquorice is consumed before attending "Cocktail parties" in people who get gastritis on consumption of alcohol. Liquorice could be used as a concomitant treatment along with the NSAIDs in the patients who are sensitive to NSAIDs to prevent gastric ulcers. This will also act as a preventive agent for those people who are suffering from peptic ulceration due to stress. Since Liquorice has been known to Ayurveda, the ancient Indian system of Medicine and also it is natural extract without modification, it has no harmful side effects and hence can be suggested to patients without the fear of serious adverse effects.

Further study is required to establish the mechanism of action of Liquorice on the protection of gastric mucosa, in terms of inhibition of acid secretion, healing properties by tissue regeneration and also antioxidant action.

Conclusions: From this study we could conclude that water extract of licorice is an effective remedy for the gastric ulcer induced due to immobilization stress. The inflammatory changes in the gastric mucosa was reversed following treatment. A dosage of $200 \mathrm{mg} / \mathrm{kg}$ body weight was effective in relieving gastric lesions. Licorice extract is effective in preventing the ulceration when used prophylactically, which is highly useful application that can be used before alcohol intake or high spicy food consumption in people who are prone to peptic ulcer following such activities.

\section{CONFLICTS OF INTEREST}

No conflict of interest.

\section{FUNDING}

Partly funded by Student fellowship offered by MAHE, Manipal.

\section{ACKNOWLEDGEMENT}

We acknowledge the support provided by the management of Kasturba Medical College., Mangalore, India by providing animal facility and laboratory.

\section{REFERENCES}

1. Parmar NS, Jagruti $K$ Desal. A review of the current methodology for the evaluation of gastric and duodenal anti-ulcer agents. Indian Journal of Pharmacology. 1993;25:120-35.

2. Aseef Yehiyan, Sowrav Barman, Haren Varia, Stephen Pettit. Short-course highdose ibuprofen causing both early and delayed jejunal perforations in a nonsmoking man. BMJ Case Reports.

3. Warren JR, Marshall BJ. Unidentified curved bacilli on gastric epithelium in active chronic gastritis. Lancet. 1983;1:1273-5.

4. McColl KE. Clinical practice. Helicobacter pylori infection. N Engl J Med 2010;362:1597-604.

5. Perry RR, Feliberti E, Vinik A. Gastrinoma Zollinger-Ellison-Syndrome. Editors In: De Groot LJ, Chrousos G, Dungan K, Feingold KR, Grossman A, Hershman JM, Koch C, Korbonits M, McLachlan R, New M, Purnell J, Rebar R, Singer F,Vinik $A$, editors. Endotext [Internet]. South Dartmouth (MA): MDText.com, Inc.; 2000.

6. Nugroho AE, Wijayanti A, Mutmainah M, Susilowati R, Rahmawati N. Gastroprotective effect of combination of hot water extracts of Liquorice (Glycyrrhiza glabra), Pulasari Stem Bark (Alyxia reinwardtii), and Sembung Leaf (Blumea balsamifera) Against Aspirin-Induced Gastric Ulcer Model Rats. J Evid Based Complementary Altern Med. 2016;21(4):NP77-84.

7. Wittschier N, Faller G, Hensel A. Aqueous extracts and polysaccharides from liquorice roots (Glycyrrhiza glabra L.) inhibit adhesion of Helicobacter pylori to human gastric mucosa. J Ethnopharmacol. 2009;125(2):218-23.

8. Momeni A, Rahimian G, Kiasi A, Amiri M, Kheiri S. Effect of Liquorice versus bismuth on eradication of Helicobacter pylori in patients with peptic ulcerdisease. Pharmacognosy Res. 2014;6(4):341-4.

9. Luís Â, Domingues F, Pereira L. Metabolic changes after Liquorice consumption: A systematic review with meta-analysis and trial sequential analysis of clinical trials. Phytomedicine. 2018;39:17-24.

10. Foster S, Foster R, Jackson P, Song S. All sorts of tests, only one question: an unexpected cause of hypertension. BMJ Case Rep. 2017;2017.

11. Ramchandran R, Verma S, Dasgupta R, Thomas N. Bitter experience with liquorice sweetening agent resulting in apparent mineralocorticoid excess with periodic paralysis. BMJ Case Rep. 2018;2018.

12. Takagi K, Okabe S, Saziki R. A new method for the production of chronic gastric ulcer in rats and the effect of several drugs on its healing. Jpn J Pharmacol. 1969;19(3):418-26.

13. Nur Azlina Mohd Fahami, Ibrahim Abdel Aziz Ibrahim, Yusof Kamisah, Nafeeza Mohd Ismail. Palm vitamin E reduces catecholamines, xanthine oxidase activity and gastric lesions in rats exposed to water-immersion restraint stress. BMC Gastroenterology 2012;12:54.

14. Shay H, Komorov SA, Fele SS, Meranzi D, Gruenstein M, Siplet H. Gastroenterol. 1945;5:43-61.

15. Rao CM, Ramesh KV, Bairy LK, Kulkarni DR. Indian Drugs. 1990;28:64-7.

16. Soxhlet F. Die gewichtsanalytische Bestimmung des Milchfettes". Dingler's Polytechnisches. 1879;232:461-5.

17. Basile AC, Sertié JA, Panizza S, Oshiro TT, Azzolini CA. Pharmacological assay of Casearia sylvestrisz. I: Preventive anti-ulcer activity and toxicity of the leaf crude extract. J Ethnopharmacol. 1990;30:185-7.

18. Ghader Jalilzadeh-Amina, Vahid Najarnezhada, Ehsan Anassoria, Mostafa Mostafavib, Hadi Keshipourc. Antiulcer properties of Glycyrrhiza Glabra L. extract on experimental models of gastric ulcer in mice. Iranian Journal of Pharmaceutical Research. 2015;14(4):1163-70. 
19. Zheng SQ, Hong XD, Chen TS, Luo PF, Xiao SC. Effects of caspase-1 inhibitor VX765 on cold-restraint stress-induced acute gastric ulcer in mice. Zhonghua Shao Shang Za Zhi. 2017;33(11):688-93.

20. Guo S, Gao Q, Jiao Q, Hao W, Gao X, Cao JM. Gastric mucosal damage in water immersion stress: mechanism and prevention with GHRP-6. World J Gastroenterol. 2012;18(24):3145-55.
21. Nugroho $A E$, Wijayanti $A$, Mutmainah $M$, Susilowati $R$, Rahmawati $N$. Gastroprotective effect of combination of hot water extracts of liquorice (Glycyrrhiza glabra), Pulasari Stem Bark (Alyxia reinwardtii), and Sembung Leaf (Blumea balsamifera) Against Aspirin-Induced Gastric Ulcer Model Rats. J Evid Based Complementary Altern Med. 2016;21(4):NP77-84.

22. Tanideh N, Rokhsari P, Mehrabani D, Mohammadi Samani S, Sabet Sarvestan F. Ashraf MJ, et al. The healing effect of liquorice on pseudomonas aeruginosa infected burn wounds in experimental rat model. World J Plast Surg. 2014;3(2):99-106.

\section{GRAPHICAL ABSTRACT}

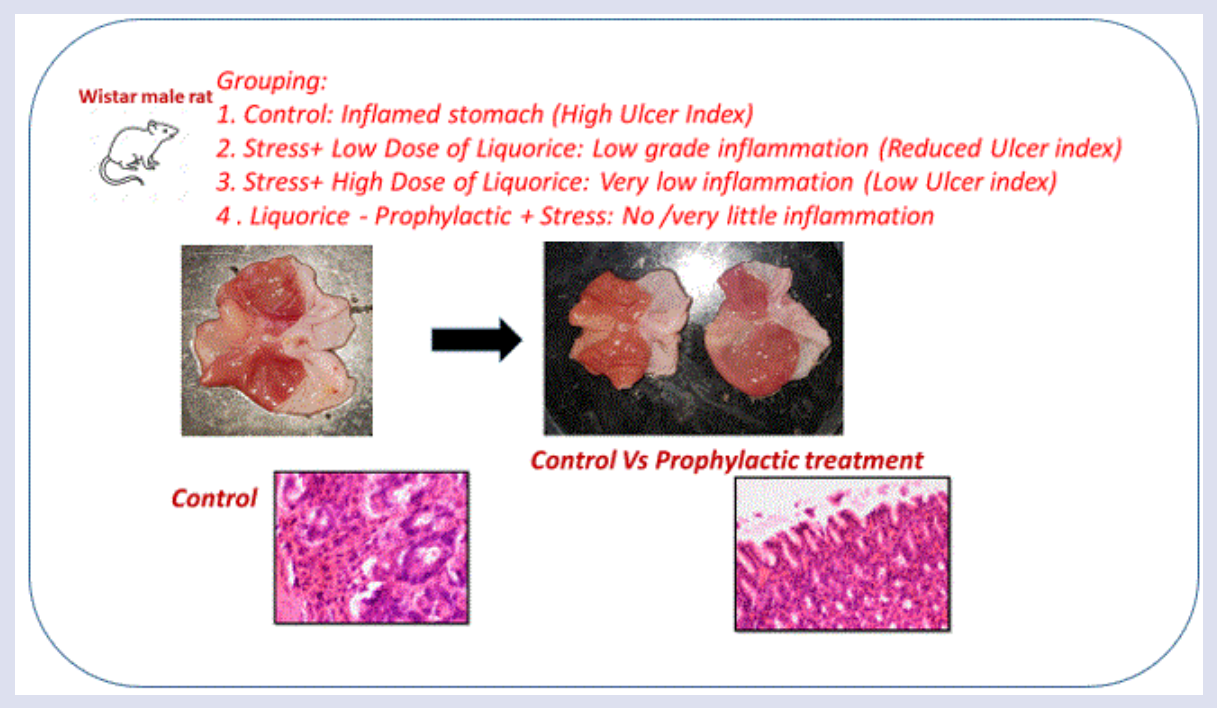

\section{ABOUT AUTHORS}

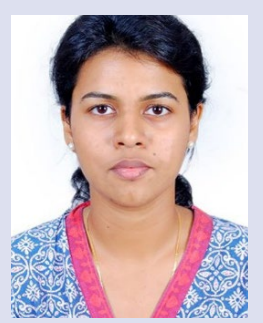

Dr Cheryl Sarah Philipose is presently working as an Assistant Professor in the Department of Pathology at Kasturba Medical College, Mangalore. She passed her MBBS from Father Muller Medical College, Mangalore in 2013. She completed her M.D in Pathology from Father Muller Medical College, Mangalore in 2016. She completed her postgraduate dissertation titled "A Histo-Morphological study of changes in neoadjuvant chemotherapy and radiotherapy in non-hematological malignancies". She has 10 publications in National and International Journals and has presented scientific papers in conferences. She secured 6th rank in MD Pathology University examination in the year 2016. Good teacher award awarded by MAHE in 2019 and prizes for poster and paper presentations in conferences. Her areas of interest include hematology, histopathology and oncopathology.

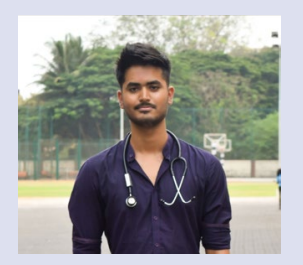

Dr Saksham Mathur is a final year Medical student in Kasturba medical college, Mangalore. He completed this research in his 2nd year with the help of his guides and secured funding from Manipal Academy of Higher Education. Along with academics and extra curricular activities, he has always been inclined towards research, so he did this project and presented the paper at an international conference in UMC, Groningen, Netherlands.

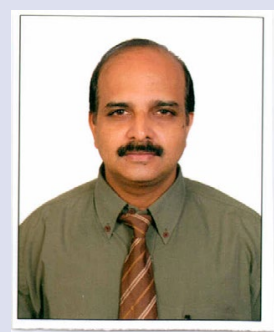

Dr Ganaraja Bolumbu Additional Professor of Physiology, Kasturba Medical College, Mangalore (A Constituent institute of MAHE, Manipal), has been active researcher since 1993 and obtained his PhD in neurophysiology of Ingestive behavior. His significant research contribution to understand control mechanism governing the ingestive behavior, where the hypothalamic ventromedial nucleus being under constant regulatory control by basolateral nucleus of amygdala. He studied role orexinergic system in regulation of food intake and addiction to alcohol in Wistar rats. Peptic ulcer is another area of his research interest. He is guide for several $\mathrm{PhD}$ thesis and undergraduate and post graduate projects. He also received DBT grant for his project. Published more than 60 research papers in reputed journals and presented papers in several national and international conferences.

Cite this article: Mathur S, Philipose CS, Ganaraja B. Effect of Aqueous Extract of Liquorice (G. Glabra L) in Treatment of Stress Induced Gastric Ulcer in Wistar Rats. Pharmacog J. 2019;11(6)Suppl:1526-31. 